\title{
Erratum to: PARP10 deficiency manifests by severe developmental delay and DNA repair defect
}

\author{
Maher Awni Shahrour ${ }^{1}$ - Claudia M. Nicolae ${ }^{2} \cdot$ Simon Edvardson ${ }^{3,4} \cdot$ Motee Ashhab $^{1}$. \\ Adri M. Galvan ${ }^{2}$ - Daniel Constantin ${ }^{2}$ - Bassam Abu-Libdeh ${ }^{1}$. \\ George-Lucian Moldovan ${ }^{2}$ - Orly Elpeleg ${ }^{4}$
}

Published online: 11 February 2017

(C) Springer-Verlag Berlin Heidelberg 2017

Erratum to: Neurogenetics (2016) 17:227-232

DOI 10.1007/s10048-016-0493-1

The original version of this article inadvertently contained a mistake.

The Acknowledgment section of the paper states that the work was supported by the following grants: NIH 1R01ES026184, Department of Defense CA140303. However, NIH 1R01ES026184 and CA140303 funds were not used in the performance of this work. These grants were mistakenly included in the original paper.

The online version of the original article can be found at http://dx.doi.org/ 10.1007/s10048-016-0493-1.

George-Lucian Moldovan

gmoldovan@hmc.psu.edu

$\triangle$ Orly Elpeleg

elpeleg@hadassah.org.il

1 Department of Pediatrics, Al-Makassed Islamic Hospital, Jerusalem, Israel

2 Department of Biochemistry and Molecular Biology, The Pennsylvania State University College of Medicine, Hershey, PA 17033, USA

3 Pediatric Neurology Unit, Hadassah, Hebrew University Medical Center, Jerusalem, Israel

4 Monique and Jacques Roboh Department of Genetic Research, Hadassah, Hebrew University Medical Center, Jerusalem, Israel 